\title{
Clinical Utility of Electronic Balance Board and Treadmill Training in Pott's Paraparesis: A Case Study
}

\section{Dildip Khanal $^{1 *}$, Subhash Khatri², RM Singaravelan³ and Deepak Anap ${ }^{2}$}

${ }^{1}$ College of Physiotherapy, Pravara Institute of Medical Sciences (PIMS), Loni (Bk), India

${ }^{2}$ Department of Orthopedic Physiotherapy, India

${ }^{3}$ Department of Neuro Physiotherapy, India

\begin{abstract}
Background: Pott's Paraparesis is one of the serious manifestations of Tuberculosis of Spine. The presence of Post Polio Residual Paralysis (PPRP) in one of the lower extremity adds to the seriousness of the sufferer. There is hardly any study about the electronic balance board and treadmill training in patients with Pott's Paraparesis as well as PPRP. Therefore, the objective of this study was to find out the clinical utility of electronic balance board and treadmill training.
\end{abstract}

Methods: A 33 years old male patient with a diagnosis of early onset grade 2 Pott's Paraparesis for eight months along with right lower limb PPRP since childhood participated in this study. He was trained with Electronic Balance Board training for 15 minutes, Treadmill Training for 20 minutes and conventional physiotherapy for 45 minutes of 36 sessions over the period of six weeks and the outcome was assessed with Berg Balance Scale (BBS), Electronic Balance Board Score (EBBS), Spinal Cord Independence Measure (SCIM), Walking Index for Spinal Cord Injury (WISCl) and Computer Dyno Graphy (CDG)® system.

Results: The results of this study showed $41.07 \%$ improvement in BBS, $50 \%$ in EBBS, $13 \%$ in SCIM, $30 \%$ in WISCl and in gait parameters such as Left/Right symmetry by $3.38 \%$, single support time (left by $4.57 \%$, right by $13.93 \%$ ), double support time (left by $62.92 \%$, right by $56.03 \%$ ), single swing (left by $13.93 \%$, right by $15.23 \%$ ), stance (left by $49.16 \%$, right by $47.64 \%$ ) and step time (left by $45.14 \%$, right by $43.20 \%$ ).

Conclusion: Electronic Balance Board and Treadmill Training may be used as an adjunct to Conventional Physiotherapeutic Rehabilitation of Pott's Paraparesis along with PPRP patient.

Keywords: Computer dyno graphy; Pott's paraparesis; Post polio residual paralysis; Balance; Treadmill; Physiotherapy

\section{Introduction}

Tuberculosis (TB) is an ancient disease that perhaps represents a dynamic balance between human and Mycobacterium tuberculosis [1]. Almost, one third of world's population is thought to have been infected with tuberculosis and $80 \%$ of populations affected are from Asia and Africa [2]. India is highest tuberculosis burdened country with an annual incidence of 2.3 million cases at 185 per 100,000 populations and an estimated prevalence of 3.1 million cases with a rate of 256 per 100,000 populations [3]. Skeletal TB accounts for $6.6 \%$ of extra-pulmonary cases of tuberculosis. Interestingly, $50 \%$ of skeletal tuberculosis involves vertebral column and the affliction is known as Potts's disease after the famous English Surgeon Sir Percival Pott [4-6]. The two major complications of Pott's disease are neurological deficit and the kyphosis. The affection of neurological deficit accounts 10 to $30 \%$, leading to a serious crippling and distressing complication called as Pott's Paraperesis. Pott's Paraparesis, a non-traumatic spinal cord injury (NTSCI) with clinical features of clumsiness, spasticity, extensor plantar response, exaggerated reflexes, sustained clonus of patella and ankle along with spontaneous twitching of muscles in lower limbs may add to obscurity in balance and gait [2]. The ultimate goal of individuals with these complications is to maximize their independence in all aspects of life within the limitations imposed by the disease process [4-6]. For this reason, balance and gait re-training perhaps plays an important role to make them independent as much as possible. Training for these components becomes more challenging especially when there is associated uncommon co-morbidity like Post Polio Residual Paralysis (PPRP). PPRP is one of the known delayed late stage manifestation of poliomyelitis characterized by patchy or asymmetrical muscle paralysis secondary to the damage to lower motor neuron, wasting, and typical deformities of extremities often involving lower limbs creating limb length discrepancy, which in turn may produce functional problems relating to balance and gait [7].

Positive effects of balance re-training and treadmill training have been reported in traumatic spinal cord injury. However, there is hardly any study about non-traumatic spinal cord injuries like Pott's Paraparesis associated with PPRP [8-13].

\section{Materials and Methods}

\section{Participant profile}

A 33 years old male patient, hotel owner by occupation with a diagnosis of D7-9 early onset grade 2 Pott's Paraparesis for eight months along with right lower limb PPRP since childhood, reported to Neuro-Physiotherapy Department with complaints of difficulty in standing balance and walking without support. His pre interventional Spinal Cord Independence Measure score (SCIM) was 77/100 and it was noted that mobility components were more affected [14]. Patient presented with right side limb length discrepancy of two centimeters, right structural scoliosis, left side elevated hip/pelvis and depressed shoulder on left side. Patient was able to ambulate using walking frame

*Corresponding author: Dildip Khanal, Postgraduate Student, College of Physiotherapy, Pravara Institute of Medical Sciences (PIMS), Loni (Bk), Rahata, Ahmed Nagar, Maharashtra State, India, E-mail: dildip_1988@hotmail.com

Received October 28, 2012; Accepted November 26, 2012; Published November 28, 2012

Citation: Khanal D, Khatri S, Singaravelan RM, Anap D (2013) Clinical Utility of Electronic Balance Board and Treadmill Training in Pott's Paraparesis: A Case Study. J Spine 2:126. doi:10.4172/2165-7939.1000126

Copyright: $\odot 2013$ Khanal D, et al. This is an open-access article distributed unde the terms of the Creative Commons Attribution License, which permits unrestricted use, distribution, and reproduction in any medium, provided the original author and source are credited. 
along with thoracolumbosacral orthosis for spinal support. He had positive Romberg's sign. His pre interventional score for Berg Balance Scale (BBS) was 11/56 [15], and Walking Index for Spinal Cord Injury (WISCI) was 13/21 [16-18].

His superficial sensations were intact bilaterally in lower limbs while deep sensations including vibration and proprioception were affected at the dermatome level L3, 4, 5 and S1. Motor functions in upper extremity were normal. In the lower extremity motor functions were measured by Lower Extremity Motor Score (LEMS) as per the guidelines given by International Standards for Neurological Classification of Spinal Cord Injury and the score was 28/50 [19]. Right leg being more affected than left. Muscle tone in left hip extensor, hip adductor, knee flexor and plantar flexor was hypertonic with grade 1 spasticity according to Modified Ashworth Scale [20]. While the tone in right leg was hypotonic, deep tendon reflexes in left leg were exaggerated, whereas in right leg they were depressed. There was extensor plantar reflex on left leg. Active range of motion was grossly within the functional limits and passive range was full; except for right ankle dorsiflexion where passive range was 5 degree. To summarize, there was Upper Motor Neuron Lesion features in left leg while Lower Motor Neuron Lesion in right leg.

\section{Training protocol}

After correcting the limb length discrepancy by shoe modification, the patient underwent the following interventions along with thoracolumbosacral orthosis for once in a day, 6 days per week for 6 weeks.

\section{Balance training}

Dynamic balance re-training was done with Electronic Balance Board with MFT-1.7 software manufactured by My Fitness Trainer Company (www.myfitnesstrainer.net) for 15 minutes a day [21]. During this training session, participant stood on an Electronic Balance Board and he was instructed to see the computer display, which was kept in front of him for visual feedback. He was asked to shift his center of pressure in form of arrow as per displayed on a monitor in the target center of green circle as much as possible. Chances of improvement in score increases as patient maintain his center of pressure in the target centre of circle. Therapist provided initially maximum support to the patient at the pelvic region. As the patient's balance improved, the support from the therapist was gradually reduced. Patient was trained for forward, backward and sideways balance. At the end of training, the test was repeated and the displayed score on the computer screen was noted (Figure 1).

\section{Treadmill training}

Before Treadmill training (EURO FITNESS POLAR NEXCUS, model number NF612026), vital signs were assessed and noted. The session ended in 20 minutes [22,23]. Patient was educated to incorporate the strategies, which he learned previously during the walking as a part of his everyday life [24]. In order to facilitate improvement in walking ability, the different variables were manipulated in Treadmill environment like treadmill speed, manual assistance and verbal cues. The goal with treadmill speed was to set it as close as possible to normal walking speed without elevation. Therefore, the speed gradually increased from $0.8 \mathrm{~km} / \mathrm{hr}$ to $1.5 \mathrm{~km} / \mathrm{hr}$ according to patient's ability [25]. Initially the patient was asked to hold the handrail of treadmill for maximum support while the therapist provided manual support at the pelvic region. As the walking ability improved, the support of handrail was gradually reduced and verbal cues were given for maintaining an upright posture to maintain the balance (Figure 2).

\section{Conventional physiotherapy}

This was in form of therapeutic positioning, chest physiotherapy, upper limb strengthening, abdominal and back extensor strengthening, lower limb strengthening, passive stretching, transfers and gait retraining for 45 minutes [26-28].

\section{Outcomes measures}

Over the period of six weeks, patient participated in 36 training sessions and patient participated in all the training sessions. His pre and post interventional outcome measures were in form of BBS, EBBS, WISCI, Computer Dyno Graphy (CDG) ${ }^{\circledR}$ Infotronic, Netherlands, http://www.infotronic.nl (Figure 3) and SCIM were recorded on before the first session and after the completion of the last session.

\section{Results}

In results, the scores revealed $41.07 \%$ improvement in BBS, $50 \%$ in EBBS, $13 \%$ in SCIM, $30 \%$ in WISCI. The improvements in the gait parameters such as Left/Right symmetry was by $3.38 \%$, single support time (left was by $4.57 \%$ and right by $13.93 \%$ ), double support time (left was by $62.92 \%$ and right $56.03 \%$ ), single swing (left was by $13.93 \%$ and right by $15.23 \%$ ), stance (left was by $49.16 \%$ and right by $47.64 \%$ ), step time (left was by $45.14 \%$ and right by $43.20 \%$ ). Inspite of

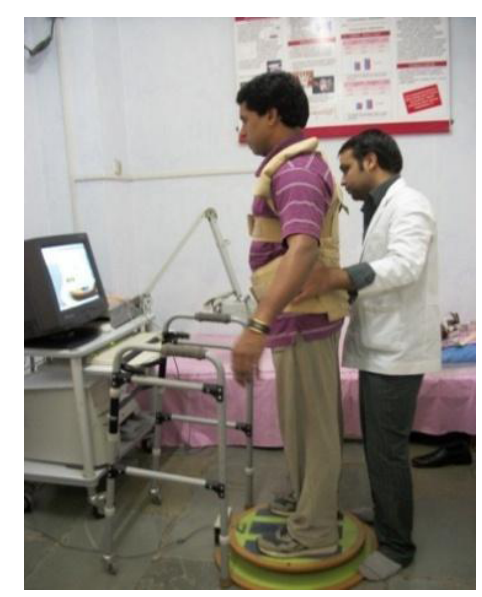

Figure 1: Electronic balance board re-training.

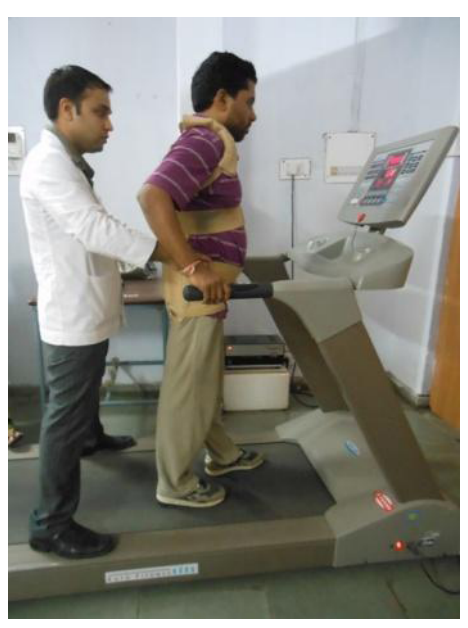

Figure 2: Treadmill Training. 
these improvements in the gait parameters, he could not achieve the normal values except for right leg single support time and left single swing time. In addition to this patient expressed $40 \%$ improvement in his physical and functional status as a result of these interventions and he could walk comfortably with a quadripod cane in right hand rather than left hand and expressed that he can even walk few steps without any support especially when he wanted to move around in his room for toilet purpose (Tables 1 and 2) (Figures 4 and 5).

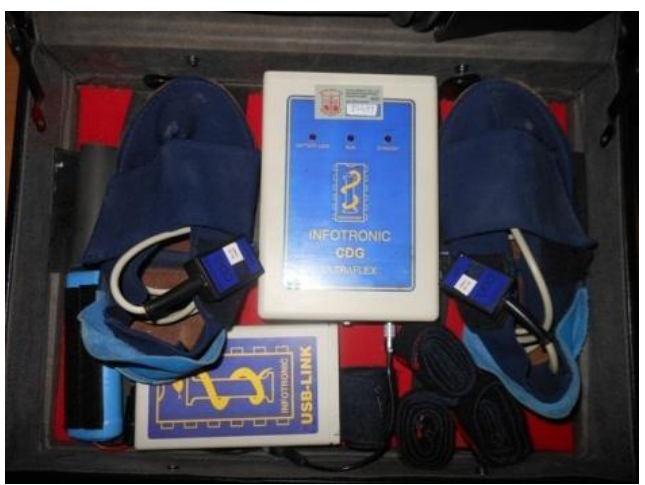

Figure 3: Computer Dyno Graphy (CDG)® System.

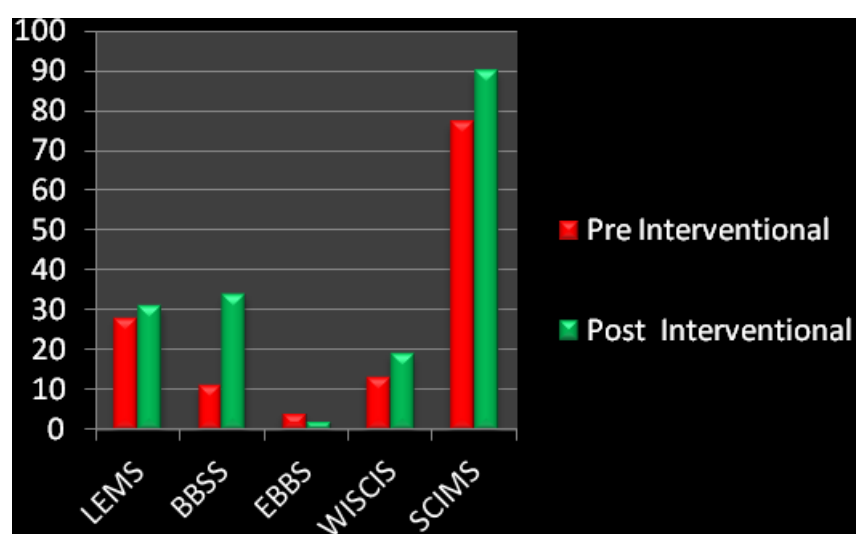

Figure 4: Graphical representation of Pre and Post Interventional Scores.

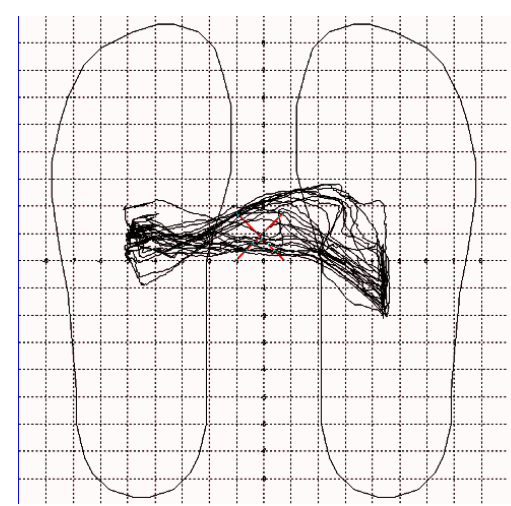

Figure 5: Cyclogram-The 'Center of Gravity' of the forces displayed for both feet combined. The Cyclogram has a time cursor $(X)$ that synchronized with the time cursors of other analyses.

\section{Discussion}

In this case, after 36 sessions of balance re-training with electronic balance board, treadmill training and Conventional Physiotherapy, there was reasonable improvement in physical and functional abilities in terms of Berg Balance Scale Score, Electronic Balance Board Score, Walking Index for Spinal Cord Injury Score, Computer Dyno Graphy, Lower Extremity Motor Score and Spinal Cord Independence Measure Score. An improvement in BBS score by $41.07 \%$ and $50 \%$ in EBBS was noted after the intervention period, this could be due to intensive training or conditioning, enhancement in nonpostural muscular use pattern, compensatory postural strategy, increase in neuro-transfer between the brain and the effector muscles through the descending pathways, facilitation of neural pathways, enhanced vestibulo-cocchlear pathways, sensory-motor integration and neuroplasticity. In addition, by giving the participant objective visual feedback, they became more aware of the body displacement and orientation in space, they were able to integrate somatosensory and visual information in relation to stance and movements, which may recalibrate deficient proprioceptive information and compensate the sensorimotor deficit [29-32]. This is in accordance with Sayenko et al. [33] who performed a study in people with incomplete spinal cord injury to find the effect of balance training with visual feedback and found similar improvement in balance [33].

Walking Index for Spinal Cord Injury was used to measure walking capacity of the participant at self-selected speed. Thirty percentage of encouraging change was noted in walking index. This may be due to gait re-training, improvement in strength of lower extremities, recovery from disease process as a result of antitubercular drugs, improved balance, self-motivation and confidence, compensation in limb length discrepancy, changed physical and functional fitness status, change in assistive device in form of quadripod cane instead of walking frame. These results are in partial accordance with Behrman et al. [34] who have reported analogous improvement in Walking Index for Spinal Cord Injury after giving locomotor training in incomplete spinal cord injury patients [34].

Computer Dyno Graphy was used to measure the gait parameters such as Left/Right symmetry, single support time, double support time, single swing, and stance and step time. The noticeable improvement in all the gait parameters could be due to treadmill training, which can be considered as "forced use" which maximizes the use of the paretic limb through a large number of steps and consequently a greater amount of load bearing and activation of the paretic muscles predominantly at faster speed [35]. Step training, which also helps to re-organize the spinal cord connections and uses the spinal cord plasticity and memory to learn the movement of locomotion [26]. In addition, axon sprouting may underlie the functional re-organization of the spinal cord to aid the re-learning of gait [26]. Lower Extremity Motor Score was used to measure the strength of bilateral lower extremities, which shows $6 \%$ of noticeable improvement. This may be due to strength training over the period of six weeks. Lastly, Spinal Cord Independence Measure was used to evaluate his functional independence. The improvement of $13 \%$ could be due to re-training for various task-specific exercises, improved balance, and muscular strength. Therefore, intensive mobility training which incorporated functional strengthening, balance and practice on a variety of walking tasks, improves balance and gait. Since there is hardly any similar study in the past, precise interpretation of finding with previous studies could not be done.

Obvious limitations of this study included the research design itself in form of single case study that limits generalization of the concepts to other individuals with similar problems and short-term follow up for 
Citation: Khanal D, Khatri S, Singaravelan RM, Anap D (2013) Clinical Utility of Electronic Balance Board and Treadmill Training in Pott's Paraparesis: A Case Study. J Spine 2:126. doi:10.4172/2165-7939.1000126

Page 4 of 5

\begin{tabular}{|l|l|l|l|}
\hline S.No. & List of Scores & Pre Interventional & Post Interventional \\
\hline 1. & Lower Extremity Motor Score (LEMS) & $28 / 50$ & $31 / 50$ \\
\hline 2. & Berg Balance Scale Score (BBSS) & $11 / 56$ & $34 / 56$ \\
\hline 3. & Electronic Balance Board Score (EBBS) & 4 & 2 \\
\hline 4. & Walking Index for Spinal Cord Injury Score (WISCIS) & $13 / 20$ & $19 / 20$ \\
\hline 5. & Spinal Cord Independence Measure Score (SCIMS) & $77 / 100$ & $50 / 100$ \\
\hline
\end{tabular}

Table 1: Pre and Post Interventional Scores.

\begin{tabular}{|c|c|c|c|c|c|c|c|}
\hline \multirow{2}{*}{ S. No. } & \multirow{2}{*}{ Gait Parameters } & \multicolumn{2}{|c|}{ Pre Interventional } & \multicolumn{2}{|c|}{ Post Interventional } & \multicolumn{2}{|c|}{ Percentage Change } \\
\hline & & Left & Right & Left & Right & Left & Right \\
\hline 1. & Single support (Sec.) & 0.722 & 0.610 & 0.689 & 0.525 & 4.57 & 13.93 \\
\hline 2. & Double support (Sec.) & 1.648 & 1.392 & 0.611 & 0.612 & 62.92 & 56.03 \\
\hline 3. & Single swing (Sec.) & 0.610 & 0.722 & 0.525 & 0.612 & 13.93 & 15.23 \\
\hline 4. & Stance (Sec.) & 3.761 & 3.540 & 1.912 & 1.748 & 49.16 & 47.64 \\
\hline 5. & Step time (Sec.) & 2.370 & 2.002 & 1.300 & 1.137 & 45.14 & 43.20 \\
\hline 6. & Symmetry Left/Right & 1.18 & & 1.14 & & 3.38 & \\
\hline
\end{tabular}

Table 2: Pre and Post Interventional study of gait parameters using Computer Dyno Graphy (CDG)® system.

only six weeks so it is recommended to perform similar studies with larger sample with long term follow up.

Therefore, authors conclude that Electronic Balance Board and Treadmill Training may be used as an adjunct to Conventional Physiotherapeutic Rehabilitation of Pott's Paraparesis along with PPRP patient.

\section{References}

1. Kumar V, Abbas AK, Fausto N, Mitchell RN (2007) Robbins Basic Pathology. (8thedn), Saunders Elsevier.

2. http://www.who.int/mediacentre/factsheets/fs104/en/index.html.

3. Global TB Control 2011: WHO Report 2011. WHO 2011

4. Sternbach G (1996) Percivall Pott: tuberculous spondylitis. J Emerg Med 14: 79-83.

5. S M Tuli (2004) Tuberculosis of the Skeletal System: Bones, Joints, Spine and Bursal Sheaths. (3rdedn), Jaypee Brothers Medical Publishers (P) Ltd, New Delhi, India.

6. Kizony R, Raz L, Katz N, Weingarden H, Weiss PL (2005) Video-capture virtual reality system for patients with paraplegic spinal cord injury. J Rehabil Res Dev 42: 595-608.

7. J. Maheshwari (2009) Essential Orthopedics. (3rdedn), Mehta Publisher, New Delhi, India.

8. Field-Fote EC (2001) Combined use of body weight support, functional electric stimulation, and treadmill training to improve walking ability in individuals with chronic incomplete spinal cord injury. Arch Phys Med Rehabil 82: 818-824.

9. Behrman AL, Harkema SJ (2000) Locomotor training after human spinal cord injury: a series of case studies. Phys Ther 80: 688-700.

10. Nymark J, DeForge D, Barbeau H, Badour M, Bercovitch S, et al. (1988) Body weight support treadmill gait training in the subacute recovery phase of incomplete spinal cord injury. Neurorehabil Neural Repair 12: 119-136.

11. Protas EJ, Holmes SA, Qureshy H, Johnson A, Lee D, et al. (2001) Supported treadmill ambulation training after spinal cord injury: a pilot study. Arch Phys Med Rehabil 82: 825-831.

12. Betker AL, Desai A, Nett C, Kapadia N, Szturm T (2007) Game-based exercises for dynamic short-sitting balance rehabilitation of people with chronic spinal cord and traumatic brain injuries. Phys Ther 87: 1389-1398.

13. Kizony R, Raz L, Katz N, Weingarden H, Weiss PL (2005) Video-capture virtual reality system for patients with paraplegic spinal cord injury. J Rehabil Res Dev 42: 595-608.

14. Itzkovich M, Tripolski M, Zeilig G, Ring H, Rosentul N, et al. (2002) Rasch analysis of the Catz-Itzkovich spinal cord independence measure. Spinal Cord 40: 396-407.

15. Lemay JF, Nadeau S (2010) Standing balance assessment in ASIA D paraplegic and tetraplegic participants: concurrent validity of the Berg Balance Scale. Spinal Cord 48: 245-250.
16. Kim MO, Burns AS, Ditunno JF Jr, Marino RJ (2007) The assessment of walking capacity using the walking index for spinal cord injury: self-selected versus maximal levels. Arch Phys Med Rehabil 88: 762-767.

17. Dittuno PL, Ditunno JF Jr (2001) Walking index for spinal cord injury (WISCI II): scale revision. Spinal Cord 39: 654-656

18. Morganti B, Scivoletto G, Ditunno P, Ditunno JF, Molinari M (2005) Walking index for spinal cord injury (WISCI): criterion validation. Spinal Cord 43: 27-33.

19. Susan B O'Sullivan, Thomas J Schmitz (2007) Traumatic Spinal Cord Injury: Physical Rehabilitation. (5thedn), Jaypee Brothers Medical Publishers (P) Ltd, New Delhi, India.

20. Michael P Barnes, Garth R Johnson (2008) Upper Motor Neurone Syndrome and Spasticity: Clinical Management and Neurophysiology. (2ndedn), Cambridge University Press, New York.

21. Susan LK, Debra JR, Clark S (1999) Balance Training for Adults with Multiple Sclerosis: Multiple Case Studies; Neurological Report 23

22. Field-Fote EC, Roach KE (2011) Influence of a locomotor training approach on walking speed and distance in people with chronic spinal cord injury: a randomized clinical trial. Phys Ther 91: 48-60.

23. Nooijen CF, Ter Hoeve N, Field-Fote EC (2009) Gait quality is improved by locomotor training in individuals with $\mathrm{SCl}$ regardless of training approach. $J$ Neuroeng Rehabil 6: 36

24. Harkema S, Behrman A. (2002) Locomotor Training: Principles and Practice. (1stedn). Culver City, Calif: Robomedica.

25. Craik RL, Dutterer L (1995) Spatial and Temporal Characteristics of Foot Fal Patterns. In: Criak RL, Oatis CA, eds. Gait Analysis: Theory and Application. St Louis, Miss: Mosby-Year Book.

26. Ida Bromley (2006) Tetraplegia and Paraplegia. A guide for physiotherapists. (6thedn), Elsevier Ltd.

27. Anwer S, Equebal A, Kumar R (2012) Effect of Treadmill Training on Gait and Functional Independence in patients with Incomplete Spinal Cord Injury: A Case Series. The Internet Journal of Allied Health Sciences and Practice 10.

28. Bizzarini E, Saccavini M, Lipanje F, Magrin P, Malisan C, et al. (2005) Exercise prescription in subjects with spinal cord injuries. Arch Phys Med Rehabil 86: 1170-1175.

29. Walker C, Brouwer BJ, Culham EG (2000) Use of visual feedback in retraining balance following acute stroke. Phys Ther 80: 886-895

30. Cheng PT, Wang CM, Chung CY, Chen CL (2004) Effects of visual feedback rhythmic weight-shift training on hemiplegic stroke patients. Clin Rehabil 18: 747-753.

31. Dault MC, de Haart M, Geurts AC, Arts IM, Nienhuis B (2003) Effects of visua center of pressure feedback on postural control in young and elderly healthy adults and in stroke patients. Hum Mov Sci 22: 221-236.

32. Mulder T, Hulstyn W (1984) Sensory feedback therapy and theoretical knowledge of motor control and learning. Am J Phys Med 63: 226-244. 
Citation: Khanal D, Khatri S, Singaravelan RM, Anap D (2013) Clinical Utility of Electronic Balance Board and Treadmill Training in Pott's Paraparesis: A Case Study. J Spine 2:126. doi:10.4172/2165-7939.1000126

33. Sayenko DG, Alekhina MI, Masani K, Vette AH, Obata H, et al. (2010) Positive effect of balance training with visual feedback on standing balance abilities in people with incomplete spinal cord injury. Spinal Cord 48: 886-893.

34. Behrman AL, Lawless-Dixon AR, Davis SB, Bowden MG, Nair P, et al. (2005)
Locomotor training progression and outcomes after incomplete spinal cord injury. Phys Ther 85: 1356-1371.

35. Eng JJ, Tang PF (2007) Gait training strategies to optimize walking ability in people with stroke: a synthesis of the evidence. Expert Rev Neurother 7: 14171436. 